Canadian Journal of Fisheries and Aquatic Sciences, 1993, v50, n1, p133-142.

ISSN: 1205-7533

DOI: 10.1139/f93-015

http://pubs.nrc-cnrc.gc.ca/rp-ps/journalDetail.jsp?jcode=cjfas\&lang=eng

http://article.pubs.nrc-

cnrc.gc.ca/RPAS/rpv?hm=HInit\&calyLang=eng\&journal=cjfas\&volume=50\&afpf=f93-

$\underline{015 . p d f}$

(C) 1993 NRC Canada 


\title{
Growth Rate Variation and Larval Survival: Inferences from an Individual-Based Size-Dependent Predation Model
}

\author{
James A. Rice and Thomas J. Miller ${ }^{1}$ \\ Department of Zoology, North Carolina State University, Raleigh, NC 27695, USA \\ Kenneth A. Rose \\ Environmental Sciences Division, Oak Ridge National Laboratory, Oak Ridge, IN 37831, USA \\ Larry B. Crowder and Elizabeth A. Marschall \\ Department of Zoology, North Carolina State University, Raleigh, NC 27695, USA \\ and Anett S. Trebitz ${ }^{2}$ and Donald L. DeAngelis \\ Environmental Sciences Division, Oak Ridge National Laboratory, Oak Ridge, TN 37831, USA
}

\begin{abstract}
Rice, J. A., T. J. Miller, K. A. Rose, L. B. Crowder, E. A. Marschall, A. S. Trebitz, and D. L. DeAngelis. 1993. Growth rate variation and larval survival: inferences from an individual-based size-dependent predation model. Can. J. Fish. Aquat. Sci. 50: 133-142.
\end{abstract}

\begin{abstract}
We used an individual-based Monte Carlo simulation model to explore how changes in the mean and variance of growth rates of individuals in a larval fish cohort interact with size-dependent predation to affect the number and characteristics of individual survivors. Small changes in initial cohort mean growth rate can change survival over the first $60 \mathrm{~d}$ of life 10- to 30-fold. But when variance in growth rate among individuals is high, survival can be substantially higher than expected from the initial mean cohort growth rate. Selection for faster-growing individuals becomes stronger with increasing variance and increasing predation rate. In some cases, $>80 \%$ of the survivors may come from the upper $25 \%$ of the initial growth rate distribution, and the mean growth rate of the survivors may exceed twice the initial mean growth rate. When individual growth rates change from day to day rather than remaining constant, the contribution of atypical individuals is accentuated even further. Counterintuitively, most of the selection for faster-growing individuals happens only after the majority of mortality has already taken place. These results suggest that interactions between individual variability and selective mortality may have important cohort-level implications for survival in fishes.
\end{abstract}

Nous avons utilisé un modèle de simulation Monte Carlo basé sur les individus pour explorer comment les changements de la moyenne et de la variance des taux de croissance d'individus dans une cohorte de larves de poisson interagissent avec la prédation en fonction de la taille pour influer sur le nombre et les caractéristiques des individus survivants. De petits changements observés dans la cohorte initiale signifient que le taux de croissance peut changer le taux de survie pour les premiers 60 jours de la vie par un facteur de 10 à 30 . Quand la variance du taux de croissance observée chez les individus est élevée, le taux de survie peut être substantiellement plus élevé que celui qui est prévu à partir du taux de croissance initial moyen de la cohorte. La sélection favorisant les individus croissant plus rapidement devient plus forte avec une variance et un taux de prédation en progression. Dans certains cas, plus de $80 \%$ des survivants peuvent provenir des $25 \%$ supérieurs de la distribution initiale du taux de croissance, et le taux de croissance moyen des survivants peut dépasser deux fois le taux de croissance initial moyen. Quand les taux de croissance des individus changent de jour en jour au lieu de demeurer constants, la contribution des individus atypiques est accentuée encore davantage. Contrairement à ce que l'on pourrait croire intuitivement, la plus grande partie de la sélection, dans le cas des ináividus croissant rapidement, n'intervient qu'après que la plus grande partie de la mortalité ait eu lieu. Ces résultats suggèrent que les interactions entre la variabilité individuelle et la mortalité sélective peuvent avoir d'importantes implications au niveau des cohortes pour la survie des poissons.

Received September 24, 1990

Accepted September 2, 1992

Reçu le 24 septembre 1990

(JA734)

Accepté le 2 septembre 1992

$\mathbf{M}$ echanisms governing survival, and ultimately selection, operate at the level of the individual. Often, the mortality sources that regulate survival are selective, so that some individuals may be more likely to survive than

\footnotetext{
'Present address: Department of Biology, McGill University, 1205 Ave. Dr. Penfield, Montreal, Que. H3A 1B1, Canada.

${ }^{2}$ Present address: Center for Limnology, University of Wisconsin, Madison, WI 53706, USA.
}

others, based on differences in some physical, behavioral, or physiological characteristics. When the amount of variation among individuals is low, or the selective forces are weak, models that are based on population or cohort averages are appropriate to represent the mechanisms operating to produce the aggregate population parameters we observe (Lotka 1925; Ricker 1954; Beverton and Holt 1957; Cushing 1975; Hutchinson 1978). However, when individuals vary substantially in characteristics important to survival, our understanding of 
mechanisms controlling cohort recruitment and other population-level responses may be enhanced by explicitly considering the effects of individual variability (Huston et al. 1988; Caswell 1989; Crowder et al. 1992).

Recent studies suggest that surviving larval and juvenile fish typically are not drawn at random from a cohort. In some cases, larvae hatching earlier are favored over younger larvae (Peterson and Wroblewski 1984; McGurk 1986), while in others, younger larvae are favored over older ones (Methot 1983; Crecco and Savoy 1985; Rice et al. 1987b). Large individuals may exhibit higher survival than small individuals within and among years (Post and Prankevicius 1987; Henderson and Cass 1991), and several studies suggest that faster-growing larvae may be favored over slower-growing individuals (Rosenberg and Haugen 1982; Rice et al. 1987b).

For larval and juvenile fishes, body size appears to be an important variable affecting survival. Most fishes grow 2-3 orders of magnitude in mass during the first few months of life (Werner and Gilliam 1984), and some of the major sources of larval mortality (predation and starvation) are strongly size dependent (Gutreuter and Anderson 1985; Rice et al. 1987a; Miller et al. 1988; Luecke et al. 1990).

Growth rate may be an important determinant of survival, especially when size-dependent mortality is important. For example, several studies suggest that relatively small reductions in mean growth rate during the early life history may cause cohort survival to decrease $1-2$ orders of magnitude simply by prolonging the period of vulnerability to mortality sources (Chambers and Leggett 1987; Houde 1987, 1989; Pepin 1990). Growth rate variation among individuals within a cohort may also have significant effects. Growth rate and size often vary substantially among individuals within a cohort. Consequently, we might expect some individuals to differ markedly from the average fish in response to size-dependent mortality, causing the combined outcome of individual interactions to differ substantially from that for the average individual (Sharp 1987).

We used an individual-based Monte Carlo simulation model to explore how changes in the mean and variance of growth rates of a larval fish cohort might interact with size-dependent predation to affect the number and characteristics of individual survivors. In particular, we asked the following questions: How might an individual larva's probability of surviving sizedependent mortality be affected by its growth rate? We expect that variance in growth rates among individuals will lead to nonrandom survival among individuals, but what are its effects on cohort survival and the sizes and growth rates of survivors?

We based our model on the predator-prey interaction between alewife (Alosa pseudoharengus) and larval/juvenile bloater (Coregonus hoyi) because this interaction is well quantified. Rice et al. (1987b) showed that bloater recruitment in Lake Michigan was strongly influenced by size- or growth-ratedependent mortality during the first 1-2 mo of life. Luecke et al. (1990) demonstrated experimentally that predation by juvenile alewife on larval bloater was strongly size dependent and may be a major source of this mortality. However, because size-dependent relationships appear to be relatively common among fishes (Miller et al. 1988), the patterns we report may have broad relevance for fishes in general.

\section{Model Description}

The model we developed tracks the daily growth and survival of individuals comprising a larval bloater cohort as they are exposed over $60 \mathrm{~d}$ to size-dependent predation by yearling ale- wife. Predator size was held constant at $90 \mathrm{~mm}$, a representative size for yearling alewife, so that the effects of growth rate variation could be evaluated without the confounding effects of changing predator size.

In the model, all larvae start at a length of $12 \mathrm{~mm}$, the typical size at which bloater larvae first become exposed to alewife in Lake Michigan (Rice et al. 1987b). In the initial series of simulations, each individual's growth rate was held constant over time so that the effects of variation among individuals could be readily evaluated. However, in nature, individual growth rates are unlikely to remain constant, so we conducted additional simulations to evaluate the effects of temporal variability in growth rates of individuals.

The probability of an individual fish being eaten on a given day (vulnerability) is the product of three probabilities: being encountered by a predator, being attacked if encountered, and being captured if attacked (Gerritsen and Strickler 1977). Probability of capture given an attack declines strongly with increasing prey size for yearling alewife feeding on larval and juvenile bloater (Luecke et al. 1990) as is typical of fish predators preying on larvae, but the other two probabilities have not been measured. The two most important factors determining encounter rate, predator reactive distance and swimming speed (Gerritsen and Strickler 1977), are both functions of predator size and therefore remain constant in our simulations, regardless of prey size. When the third factor, prey swimming speed, is much less than predator speed as we might expect for larval bloater and yearling alewife or for other relatively large fish predators on larvae, the encounter rate remains nearly constant, increasing only slightly with prey size (Gerritsen and Strickler 1977). Alewife readily eat both larval and juvenile bloater and even prefer them to zooplankton (Luecke et al. 1990), so it also seems unlikely that probability of attack would change noticeably over the range of prey sizes occurring in our simulations. Therefore, for our simulations, we set the daily probability of prey being both encountered and attacked as a constant.

The combined result of these probabilities is monotonically declining vulnerability with increasing prey size, which is a typical pattern for many larval fish predator-prey interactions (Bailey and Houde 1989). Some species exhibit lower vulnerability in early life stages (e.g. eggs or uneyed yolk sack larvae) because encounter rate is substantially reduced by their low visibility and/or low motility (e.g. Brownwell 1985; Folkvord and Hunter 1986). This may cause a slight "hump" in the vulnerability function at very small sizes, but even for these cases, vulnerability is a declining function over much of the early ontogeny. For relatively small, slow-moving, or ambush predators (e.g. chaetognaths, jellyfish), a more pronounced domeshaped vulnerability function would be expected (Greene 1986; Bailey and Houde 1989). However, the assumption of constant probability of encounter and attack is appropriate for bloater larvae and juveniles preyed upon by yearling alewife and also produces an overall pattern of size-dependent vulnerability that is applicable to many other large, fast-swimming predators feeding on all but the smallest sizes of larvae.

The value used for the daily probability of encounter and attack governs the intensity of predation in the simulation. Clearly, changes in intensity of predation (e.g. changes in predator density) will have major effects on larval survival. Our intent was to evaluate the extent to which changes in mean and variance of larval growth rate would modify this survival rate. Therefore, we conducted all the individual-based model simulations using one value for daily probability of encounter and attack, 0.2 , that gave us substantial mortality but still left 
GROWTH RATE (mm/d) DISTRIBUTIONS

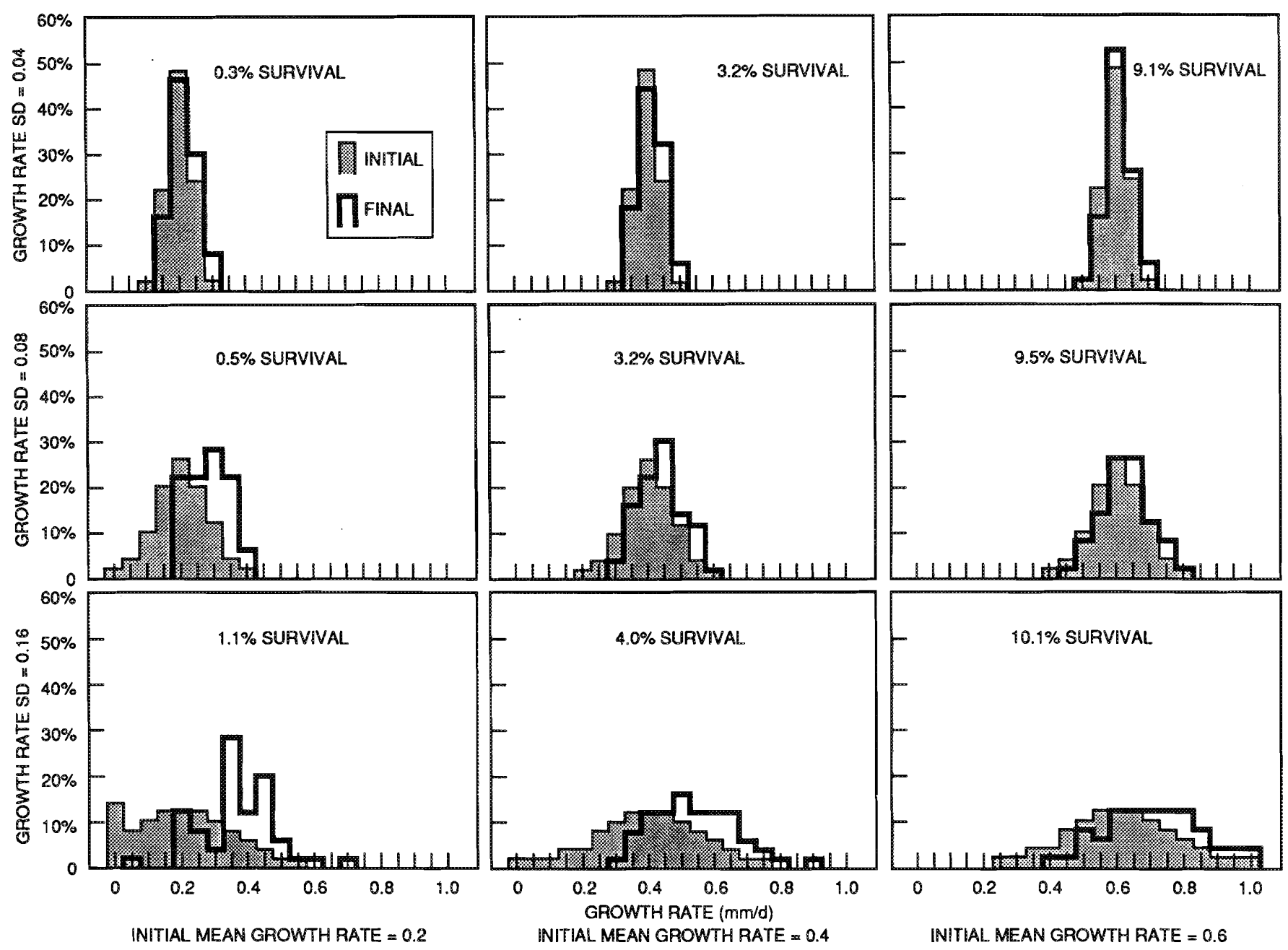

FIG. 1. Growth rate frequency distributions for cohorts of larval bloater having three initial mean growth rates $(0.2,0.4,0.6 \mathrm{~mm} / \mathrm{d})$ and three levels of variability in growth rate among individuals $(\mathrm{SD}=0.04,0.08,0.16 \mathrm{~mm} / \mathrm{d}$ ) before and after $60 \mathrm{~d}$ of size-dependent predation by 90 $\mathrm{mm}$ alewife. Values in each cell indicate the percent cohort survival after $60 \mathrm{~d}$ of predation.

enough survivors after $60 \mathrm{~d}$ for analysis. We assumed that the probability of multiple encounters and attacks on a single day was small, and therefore, we did not explicitly include it. On each day of a simulation, each fish was assigned a number drawn at random from a uniform distribution between 0 and 1 ; if the number was less than or equal to the probability of encounter and attack, an attack occurred. Whether the individual died or lived to the next day was determined by comparing a second random number beween 0 and 1 to the individual's probability of capture. Probability of capture, given an attack, was determined using the relationship between capture success and the predator-prey size ratio for $90-\mathrm{mm}$ alewife preying on larval and juvenile bloater (probability of capture $=-0.33+$ $0.15 \cdot$ (predator length/prey length); Luecke et al. 1990); capture probability was set to 0 for bloater $>40.9 \mathrm{~mm}$, the size at which capture success reached zero. At the end of each time-step, each surviving individual grew to a new size determined by its growth rate and was then exposed to predation again on the next day. We followed the numbers, size distribution, and growth rate distribution of surviving individuals throughout each simulation.

\section{Model Simulations and Results}

Our initial series of simulations was designed to examine the hypothesis that when mortality is size dependent, both increased mean growth rate and increased variance in growth rate among individuals will increase cohort survival and that survivors will be drawn nonrandomly from the cohort. We conducted nine simulations using three mean growth rates $(0.2,0.4$, and $0.6 \mathrm{~mm} / \mathrm{d}$ ), each with three different levels of variance in growth rate among individuals $(\mathrm{SD}=0.04,0.08$, and $0.16 \mathrm{~mm} /$ d). Observed means and variances of growth rates for Lake Michigan bloater fall near the middle of these ranges; in the early 1980s, Lake Michigan larval bloater growth rates typically ranged from 0.25 to $0.75 \mathrm{~mm} / \mathrm{d}$ (Rice et al. 1987b).

In these simulations, each larva was assigned a growth rate drawn at random from a normal distribution with the specified mean and variance and maintained this assigned growth rate throughout the entire simulation. Growth rates were constrained to the range of $0-1.0 \mathrm{~mm} / \mathrm{d}$; individuals drawing a growth rate below or above these bounds were assigned a growth rate of 0 or $1.0 \mathrm{~mm} / \mathrm{d}$, respectively. Several additional simulations were 
TABLE 1. Means and 95\% confidence intervals for percent survival of a larval fish cohort from $60-d$ simulations of the predation model. Each combination of growth rate mean and variance was repeated 30 times, with different random number seeds. Initial cohort size was 4000 larvae for each run. All means were significantly different from one another except for the low and intermediate variance simulations at high initial growth rate.

\begin{tabular}{cccr}
\hline \hline & \multicolumn{3}{c}{ Initial mean growth rate } \\
\cline { 2 - 4 } Growth rate SD & $0.2 \mathrm{~mm} / \mathrm{d}$ & $0.4 \mathrm{~mm} / \mathrm{d}$ & \multicolumn{1}{c}{$0.6 \mathrm{~mm} / \mathrm{d}$} \\
\hline 0.04 & $0.362 \pm 0.037$ & $3.118 \pm 0.096$ & $9.538 \pm 0.185$ \\
0.08 & $0.536 \pm 0.033$ & $3.323 \pm 0.073$ & $9.666 \pm 0.151$ \\
0.16 & $1.124 \pm 0.068$ & $4.155 \pm 0.010$ & $10.068 \pm 0.133$ \\
\hline
\end{tabular}

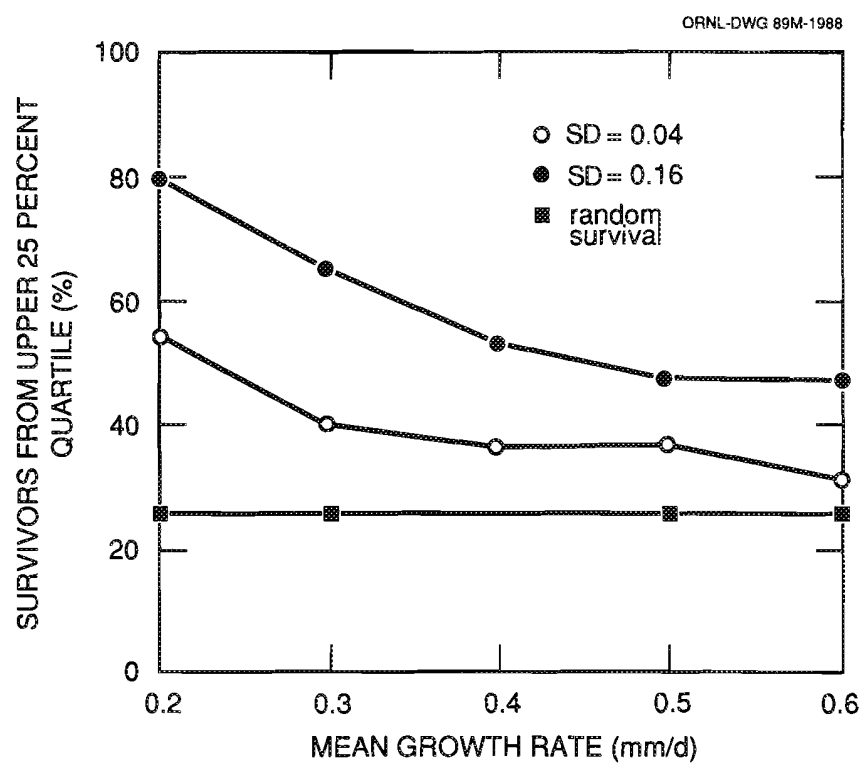

Fig. 2. Percentage of survivors after $60 \mathrm{~d}$ of size-dependent predation that came from the upper $25 \%$ of the initial growth rate distribution, plotted as a function of initial mean growth rate of the cohort, with high $(S D=0.16)$ and low $(S D=0.04)$ variability in growth rate among individuals. Level line indicates expected percentage if survival was random.

run at mean growth rates of 0.3 and $0.5 \mathrm{~mm} / \mathrm{d}$ with high or low variance.

Most simulations were started with 4000 individuals, to impose a reasonable limit on computing time. In a few runs which exhibited very low survival, we used up to 10000 individuals. The daily probability of encounter and attack was set at 0.2 . We also repeated each of the nine initial runs with this probability set to zero, so we could compare the size distribution of survivors with and without predation; these runs were initiated with only 1000 individuals because there was no mortality.

Changes in the mean and variance in growth rate had substantial effects on survival and on the growth rate distribution of survivors (Fig. 1). Survival increased 10 - to 30 -fold with increasing mean growth rate. Survival also increased up to fourfold with increasing variance in growth rate, especially when the initial mean growth rate was low.

To evaluate the significance of these changes in survival, we ran 30 simulations for each growth rate mean and variance combination and calculated $95 \%$ confidence intervals for the estimates of survival (Table 1). These results indicate that the changes in survival we observed with increasing variance or initial mean growth rate are highly significant.
In these nine initial runs, individual fish maintained the constant growth rate assigned to them at the beginning of the simulation. Thus, changes in mean growth rates of the survivors resulted from selective mortality rather than from changes in the growth rates of individuals. As mean growth rate decreased and variance increased, the growth rate of surviving individuals became increasingly different from the initial average for the cohort, indicative of selection for faster-growing individuals. For example, at the lowest growth rate and highest variance, $80 \%$ of the individuals surviving 60 d came from the upper $25 \%$ of the initial growth rate distribution (Fig. 2). Even at the highest growth rate, almost $50 \%$ of the survivors came from the upper quartile when variation in growth rate among individuals was high (Fig. 2). When initial mean growth was low, and mortality was therefore high, even the lowest level of variability was sufficient to induce fairly strong selection, with more than $50 \%$ of the survivors coming from the upper $25 \%$ of the initial growth rate distribution. In every case the distribution of growth rates of survivors was different from what would have been expected if we had modeled the population using a single mean growth rate value. Clearly, if growth rate variability and sizedependent mortality interact in natural populations, survivors will not be drawn at random from the initial growth rate distribution.

The size-distribution of survivors in our simulations also reflects the interaction between size-dependent predation and the mean and variance of growth rates. As mean growth rate decreased and variance increased, survivors from cohorts subjected to predation were much larger than those from cohorts which experienced no predation (Fig. 3). When variation in growth rate among individuals was high, the mean size of individuals surviving predation was $5-10 \mathrm{~mm}$ (about 20\%) greater than when growth rate variation was low.

Counterintuitively, in our simulations, the period of highest mortality was not coincident with the period of strongest growth rate selection. Mean growth rate changed little during the first few days when mortality was highest, and more than half the change in mean growth rate occurred during the last $1.5 \%$ of the mortality (Fig. 4). This asymmetry resulted because selective mortality was not acting directly on variability in growth rate, but on variability in size, which takes time to develop. Initially, fast- and slow-growing individuals were the same size and had the same high vulnerability to predation. While most survivors tended to be drawn from among the faster-growing individuals, most of the faster-growing fish died, along with their slow-growing counterparts, during this early period. However, because the size of fast-growing individuals was increasing rapidly, they experienced a more rapid decline in the daily probability of dying than did slow-growing individuals (Fig. 5a). Because these daily probabilities are compounded, the probability of surviving to day 60 increased much more 
FINAL LENGTH (mm) DISTRIBUTIONS

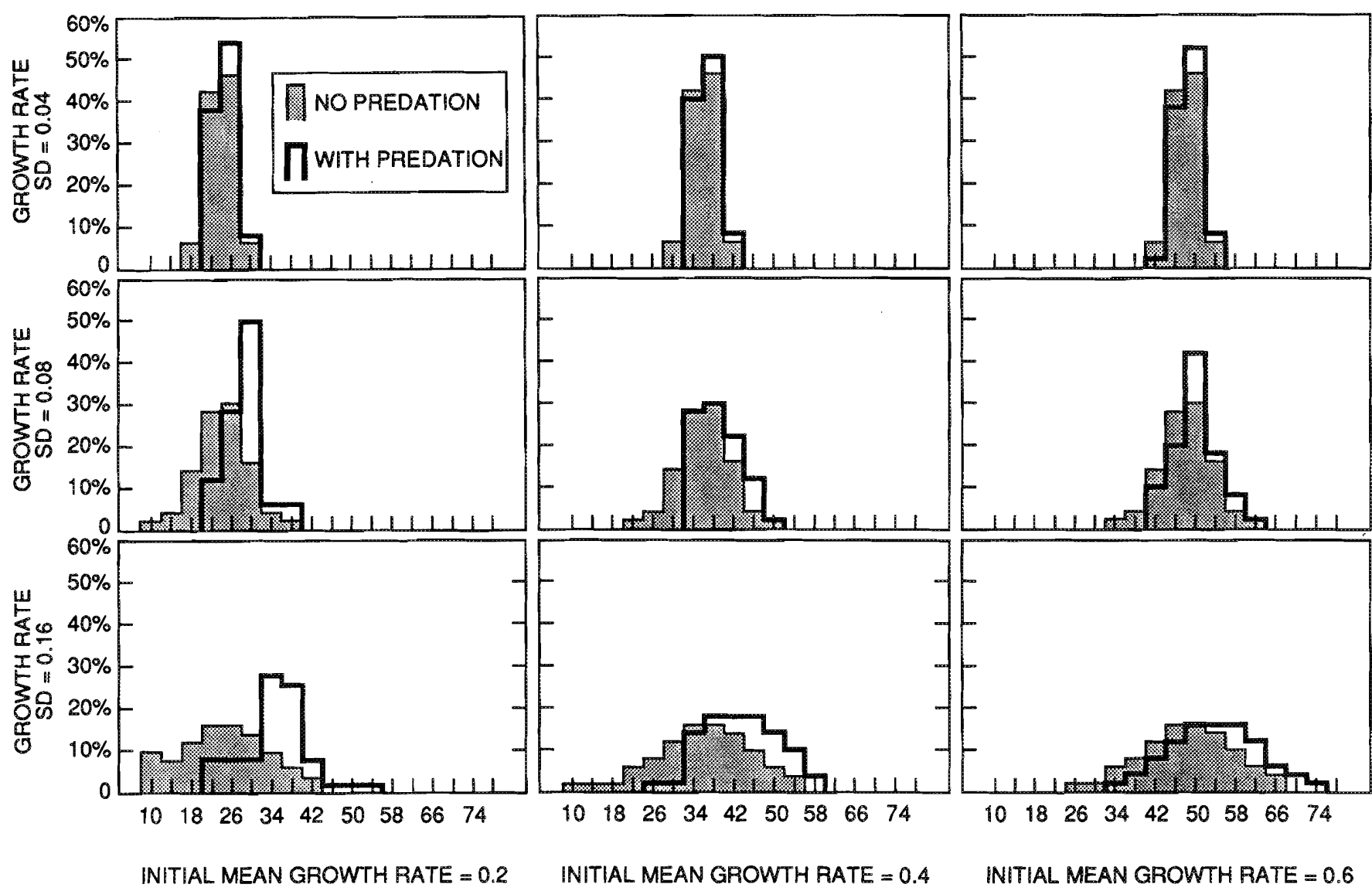

Fig. 3. Size frequency distributions for cohorts of larval bloater having three initial mean growth rates $(0.2,0.4,0.6 \mathrm{~mm} / \mathrm{d})$ and three levels of variability in growth rate among individuals $(S D=0.04,0.08,0.16 \mathrm{~mm} / \mathrm{d}$ ) after $60 \mathrm{~d}$ with and without size-dependent predation by 90 -mm alewife.

quickly for fast-growing individuals than for slow-growing fish (Fig. 5b). For example, after $10 \mathrm{~d}$, an individual growing at $0.6 \mathrm{~mm} / \mathrm{d}$ would have a $31 \%$ chance of living to day 60 , while a fish growing at $0.2 \mathrm{~mm} / \mathrm{d}$ would have only a $1.6 \%$ chance. After $30 \mathrm{~d}$, the fast-growing fish would be $30 \mathrm{~mm}$ long and have an $83 \%$ chance of surviving, while the slow-growing individual would have grown to only $18 \mathrm{~mm}$ and have only a $14 \%$ chance of living to day 60 .

The intensity of predation (i.e. encounter rate) will obviously have a major effect on the number of larvae surviving. However, higher predation mortality should also cause the effects of mean and variance in growth rate on characteristics of survivors to become even more pronounced because selective mortality is the cause of these changes. Our individual-based simulations were conservative in this regard. In order to have adequate numbers of survivors for analysis in all simulations, and work within the constraints of available computer memory and speed, we had to use a probability of encounter and attack that resulted in survival rates 1-3 orders of magnitude higher than typical estimates for fishes in the field (Forney 1976; Ware and Lambert 1985; Houde 1987; Taggart and Leggett 1987).

In contrast with our individual-based simulation model, partial differential equation (PDE) analytical models can incorporate more realistic mortality rates because they are not constrained by cohort size. Comparable PDE models cannot be developed for many individual-based simulation models, but we were able to formulate a PDE directly analogous to the simulations described above (Appendix). We used this model to evaluate the effect of predation rate on mean growth rate of surviving larvae for a cohort having an initial mean growth rate of $0.6 \mathrm{~mm} / \mathrm{d}$ and high variance. In our individual-based simulations using a daily probability of encounter and attack of 0.2 , the mean growth rate of survivors increased only $0.09 \mathrm{~mm} / \mathrm{d}$ over $60 \mathrm{~d}$ because survival was so high $(10.1 \%)$. When we used the PDE with a probability of encounter and attack of 0.7 which produced a more realistic cohort survival of $0.07 \%$, the mean growth rate of survivors increased by $0.2 \mathrm{~mm} / \mathrm{d}$. Thus, substantial selection for faster-growing individuals can occur provided sufficient variability exists among individual growth rates and the magnitude of size-dependent mortality is sufficient to impose selection. The patterns observed in our relatively conservative simulations would be further accentuated at more realistic encounter rates. Note, however, that this selection may be somewhat less at high than at low initial mean growth rates because in the former case, a larger proportion of individuals will reach less vulnerable sizes earlier.

In the simulations discussed above, individual growth rates remained constant. A more complex, but potentially more realistic, assumption would allow growth rates of individuals to vary from day to day. We modeled this process as a random walk with "memory," where individuals possessing an aboveaverage growth rate on day $t$ would have an increased proba- 

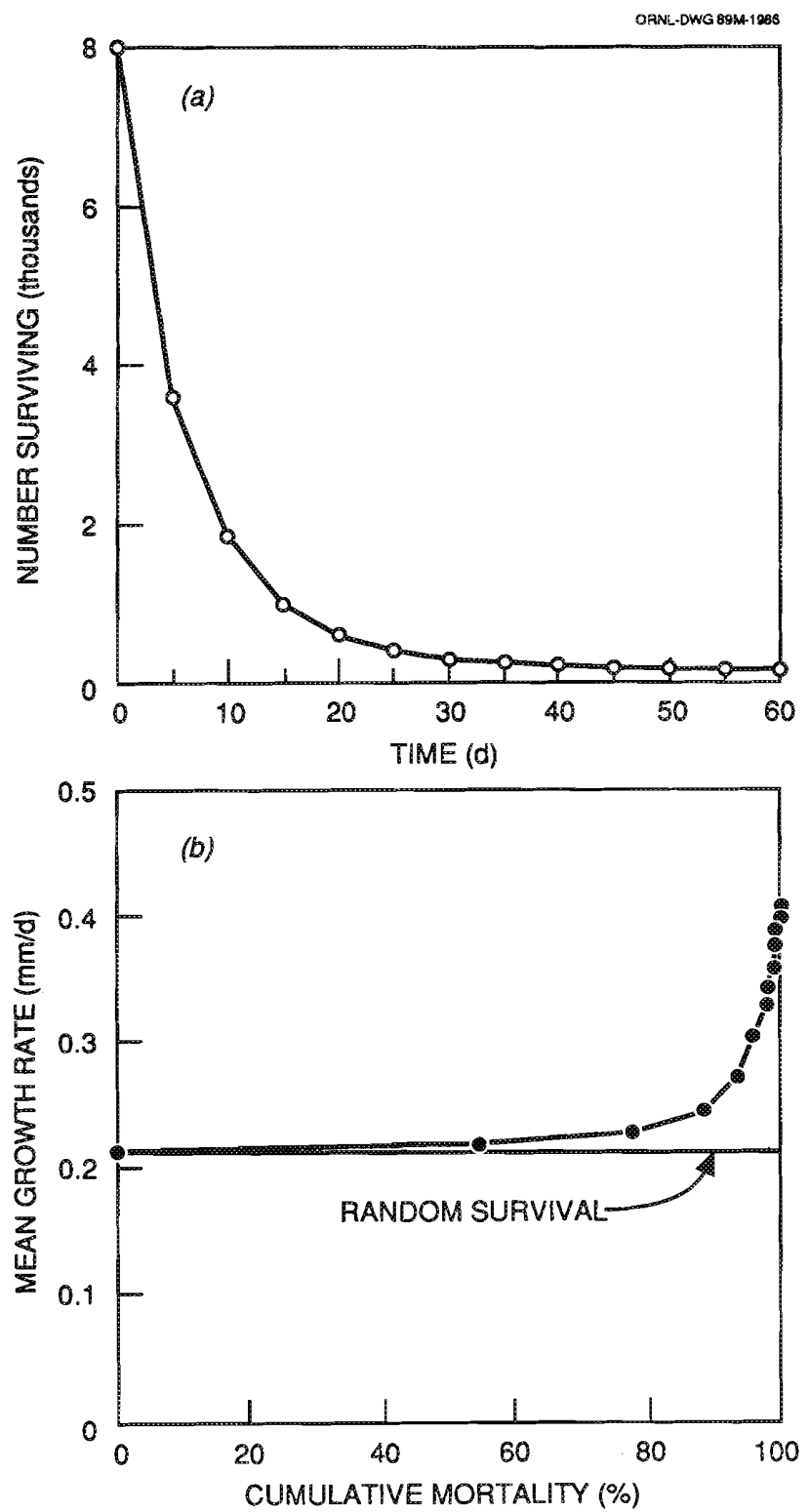

FIG. 4. (a) Survival curve for a cohort of 8000 larval bloater having an initial mean growth rate of $0.2 \mathrm{~mm} / \mathrm{d}$ and high variability in growth rate among individuals ( $\mathrm{SD}=0.16 \mathrm{~mm} / \mathrm{d}$ ), when exposed to sizedependent predation by $90-\mathrm{mm}$ alewife (daily probability of encounter and attack $=0.2$ ) for $60 \mathrm{~d}$. (b) Change in mean growth rate of surviving individuals from this same cohort as cumulative mortality of the cohort increases. Level line indicates expected result (no change in mean growth rate) if survival was random.

bility of achieving an above-average growth rate on day $t+1$, and slow-growing larvae on day $t$ would be more likely to have a below-average growth rate on day $t+1$. We performed a simulation to test the hypothesis that the increased variance in average growth rates among individuals caused by such a random walk would have an ever greater effect on the number and size distribution of survivors than when individual growth rates were held constant. In this simulation the initial growth rate of each individual was drawn at random from a normal distribution with mean growth rate $=0.4 \mathrm{~mm} / \mathrm{d}$ and $\mathrm{SD}=0.08$. On subsequent days, each individual's growth rate was drawn at random from a normal distribution of growth rates with the same variance ( $\mathrm{SD}=0.08)$, but centered on the individual's growth rate from the previous day. Growth rates were limited to the
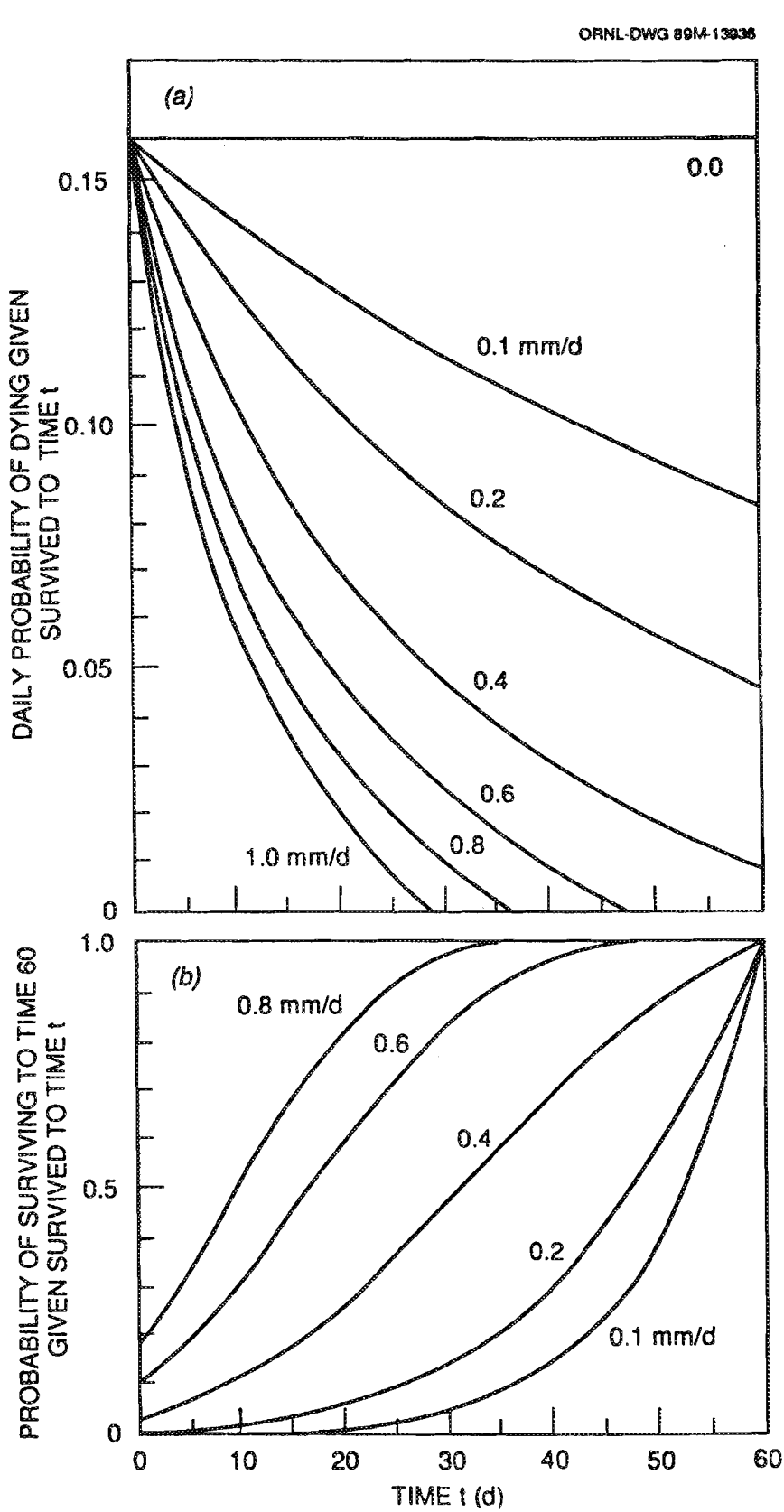

FIG. 5. (a) Change, over $60 \mathrm{~d}$, in the daily probability of being eaten for larval bloater growing at different rates $(0.0-1.0 \mathrm{~mm} / \mathrm{d})$ while exposed to size-dependent predation by $90-\mathrm{mm}$ alewife, using the probability of capture equation from Luecke et al. (1990) and a probability of encounter and attack $=0.2$. (b) Change, over $60 \mathrm{~d}$, in the probability of surviving to day 60 , given they are still alive at time $t$, for larval bloater growing at different rates while exposed to sizedependent predation by $90-\mathrm{mm}$ alewife.

range of $0-0.8 \mathrm{~mm} / \mathrm{d}$; in cases where an individual's growth rate exceeded these limits, it was set equal to the limit. This kept the boundaries symmetrical around the initial mean growth rate, so that observed changes in mean growth rate during the simulation could be attributed completely to selective mortality, rather than random drift. The simulation was run both with and without predation (probability of encounter and attack $=0.2$ or $0 / d$ ), and each of these was repeated with the growth rate of each individual held constant throughout the simulation (as in the previous simulation shown in the center panel of Fig. 1 and $3)$, for comparison. 

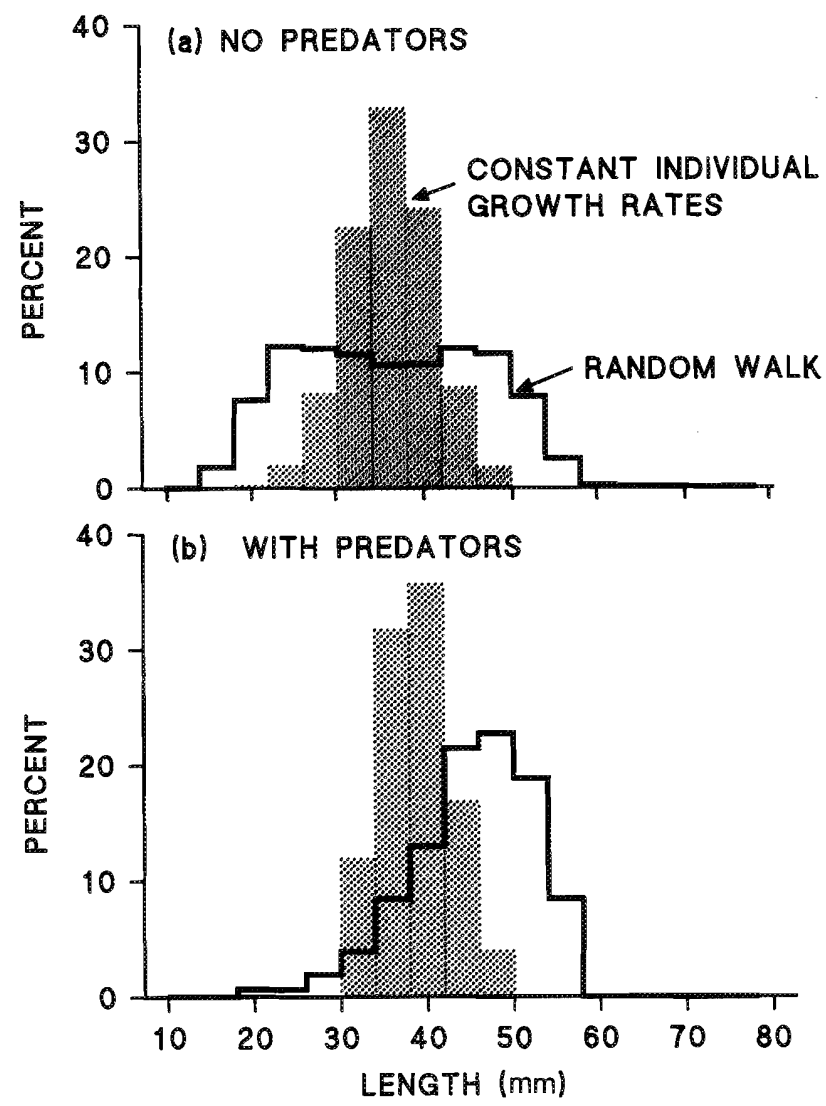

Fig. 6. Size frequency distributions after $60 \mathrm{~d}$ (a) without predation and (b) with size-dependent predation by $90-\mathrm{mm}$ alewife for two cohorts of larval bloaters; one with constant individual growth rates (as in simulation shown in center panel of Fig. 1 and 3) and the other with individual growth rates that vary daily in a random walk between 0 and $0.8 \mathrm{~mm} / \mathrm{d}$. Both cohorts started with an initial growth rate of $0.4 \mathrm{~mm} / \mathrm{d}$ and medium variability among individuals $(\mathrm{SD}=0.08 \mathrm{~mm} / \mathrm{d})$.

When individual growth rates were allowed to vary daily in a random walk, the final size distribution after $60 \mathrm{~d}$ was substantially more variable than when individual growth rates were held constant, even in the absence of predation mortality (Fig. 6a). When size-dependent predation occurred, increased growth rate variability led to an increase in both the number and average size of survivors; $3.9 \%$ of the fish from the initial cohort survived to day 60 and attained a mean length of $45.3 \mathrm{~mm}$ in the random walk simulation, while only $2.5 \%$, averaging $38.9 \mathrm{~mm}$ on day 60 , survived from the constant growth rate simulation (Fig. $6 \mathrm{~b}$ ). The mean growth rate of survivors in the random walk simulation was $0.11 \mathrm{~mm} / \mathrm{d}$ higher than that of survivors in the constant growth rate run, and $90 \%$ of the survivors had growth rates above the original mean.

\section{Discussion}

The results of our simulations clearly demonstrate that both mean growth rate and growth rate variation among individuals can interact strongly with size-dependent mortality to cause significant effects on the number, growth rates, and final sizes of survivors. Consideration of variability among individuals may reveal insights regarding the processes shaping year class strength that are not available from analyses of population parameters and the dynamics of the average individual in a cohort. Our results are consistent with Sharp's (1987) sugges- tion that the characteristics of a small fraction of individuals in the cohort may largely govern recruitment success. Our simulations suggest that cohorts starting with similar mean growth rates but different variances may produce very dissimilar numbers and sizes of survivors, even when exposed to identical mortality mechanisms. Likewise, cohorts with very different initial mean growth rates can end up with very similar mean growth rates among survivors, if the variance in growth rates among individuals is different. For example, after $60 \mathrm{~d}$ the survivors from a cohort having an initial mean growth rate of $0.4 \mathrm{~mm} / \mathrm{d}$ and low variance (upper center panel of Fig. 1) had a mean growth rate of $0.41 \mathrm{~mm} / \mathrm{d}(\mathrm{SD}=0.13)$. After $60 \mathrm{~d}$ the mean growth rate of survivors from a cohort having a low initial mean growth rate of $0.2 \mathrm{~mm} / \mathrm{d}$ and high variance (lower left panel of Fig. 1) had risen sharply to a similar value of $0.37 \mathrm{~mm} /$ $\mathrm{d}(\mathrm{SD}=0.12)$, not significantly different from the cohort with the high initial growth rate and low variance (based on $30 \mathrm{sim}$ ulations; $P=0.05, t=1.906,171 \mathrm{df}$ ).

Our simulations also suggest that even though the vast majority of the mortality experienced by a cohort of larval fish occurs shortly after hatching when larvae are most numerous and may also be most vulnerable, in some cases selective mortality such as size-dependent predation after this period may substantially alter the number of larvae that survive. In our simulations, the distribution of survival probabilities among individuals changed, with time, from uniform to very nonuniform. Thus, chance events such as weather phenomena, variable transport dynamics, or other abiotic influences may govern mortality for the majority of a cohort, but size and growth rate characteristics of individuals, through their interaction with size-specific mortality, may still influence final cohort abundance and size structure. For example, after $15 \mathrm{~d}$, our simulated cohorts with high and low growth rate variance and initial growth rate of $0.2 \mathrm{~mm} / \mathrm{d}$ both showed very similar substantial mortality (survival $=11.5$ and $11.1 \%$, respectively), but after $60 \mathrm{~d}$, survival in the high-variance cohort was nearly fourfold higher than in the low-variance simulation $(1.1$ versus $0.3 \%)$. In all our simulations, survivors tended to be fast-growing individuals, even though the vast majority of fast-growing fish still died. At the outset of our simulations, we could not predict which individuals would survive, but as growth and mortality proceeded, the outcome became increasingly clear. These results suggest that in some cases, year class strength may be set somewhat later in the early life history than has been commonly assumed (Sale 1990).

The patterns in survival, and in size and growth rate distributions, that we have simulated when keeping individual growth rates constant are conservative relative to the more realistic probability that individual growth rates will vary over time. The random walk trials we performed, which simulate this variability, suggest that when individual daily growth rates vary, the contribution of atypical individuals is further accentuated.

In the field, all mortality may not be size dependent. However, selection for fast-growing individuals may still persist. If we substitute random mortality for a portion of the size-dependent mortality, this has the same effect on the growth rate distribution as reducing the probability of encounter and attack by an equivalent proportion. We did not explicitly simulate the effects of size-dependent variation in growth rates, but such effects would also act to magnify the effects of individual variability.

The dynamics we describe emerged from simulations of small cohorts (typically 4000 individuals) with survival rates that are high relative to estimates for cohorts in the field (Forney 1976; 
Ware and Lambert 1985; Houde 1987; Taggart and Leggett 1987). Results from the analytical model (Appendix) confirmed that much stronger patterns of selectivity for fast-growing individuals occur when cohort size is larger and more realistic mortality rates are used. This is so because selectivity increases with the amount of size-dependent mortality that occurs.

The results of our simulations suggest that progress toward an understanding of recruitment processes may be accelerated by a systematic and in-depth consideration of individual variability and the attributes of survivors. The specific results of our simulations, as with any model, derived from our assumptions. Our simulations were based on two general phenomena that are observed in many fishes: variability in growth rates and size-dependent vulnerability to predation. They demonstrate the potential for individual variability to substantially affect cohort survival and size structure of the survivors. Simulations exploring different assumptions (e.g. growing predators, different initial sizes, dome-shaped vulnerability functions, etc.) may provide additional insights, and should be pursued.

Individual-based Monte Carlo simulation models like the one presented here may also be useful in helping to determine the limits on our ability to predict cohort survival because they incorporate the uncertainty inherent in processes determining survival. For example, in the simulations we repeated 30 times (Table 1), the total range of survival values was two- to threefold. These results suggest an upper bound on the ability to accurately predict year-to-year variations in survival, even if we possessed models which perfectly summarized the recruitment process.

DeAngelis et al. (1993) compared the output of individualbased models like the one presented here with continuous models based on partial differential equations to evaluate the robustness of the simulation approach. In a variety of scenarios where both simulation and PDE models were applicable, both methods gave similar results, suggesting that either approach could be used. However, when growth rates are correlated among individuals (e.g. density or size dependence of growth; Lomnicki 1988) or when growth rates are correlated within individuals from day to day (our "random walk" with memory), it is difficult to solve the appropriate PDE model. In these and other biologically interesting situations (including those involving noninearities), the simulation approach used here may provide greater insights.

Individual-based simulation models are heuristically attractive and can be developed relatively easily even for situations where analytical solutions would be difficult or impossible to formulate and solve. However, individual differences may not be equally important in all stages of the life history. In our simulations, for example, individual differences in size become unimportant after all individuals have outgrown vulnerability to the predator. Individual-based models may be helpful in defining when a simpler approach to understanding year class variation, based on population averages, may be sufficient and when effects of individual variability in characteristics important to survival, such as body size, need to be considered.

\section{Acknowledgments}

This research was sponsored by the following agencies: Electric Power Research Institute under contract No. RP2932-2 (DOE No. ERD-87-672) with the U.S. Department of Energy, under contract No. DE-AC05-840R21400 with Martin Marietta Systems, Inc.; University of Wisconsin Sea Grant College Program and the state of Wisconsin through federal grant NA800AA-D-00086, Project R/LR-37; Univer- sity of North Carolina Sea Grant College Program and the state of North Carolina through federal grant NA85AA-D-SG022, Project R/MER-12; NOAA South Atlantic Bight Recruitment Experiment (NA16RG0492-01), Project R/SAB-4; and the North Carolina Agricultural Research Station. T.J.M. and E.A.M. were supported in part by EPRI Fellowships in Population Biology administered through the Sports Fishing Institute. W. C. Leggett provided valuable comments on an earlier version of this paper. Publication No. 3971 of the Environmental Sciences Division, Oak Ridge National Laboratory.

\section{References}

Bailey, K. M., and E. D. Houde. 1989. Predation on eggs and larvae of marine fishes and the recruitment problem. Adv. Mar. Biol. 25: 1-83.

Beverton, R. J. H., AND S. J. HoLt. 1957. On the dynamics of exploited fish populations. Fish. Invest. Lond. Ser. II 19: 1-533.

BROWNWELL, C. L. 1985. Laboratory analysis of cannibalism by larvae of the cape anchovy Engraulis capensis. Trans. Am. Fish. Soc. 114: 512-518.

CASWELL, H. 1989. Matrix population models. Sinauer Associates, Inc., Sunderland, MA.

Chambers, R. C., AND W. C. LegGetr. 1987. Size and age at metamorphosis in marine fishes: an analysis of laboratory-reared winter flounder (Pseudopleuronectes americanus) with a review of variation in other species. Can. J. Fish. Aquat. Sci. 44: 1936-1947.

CRECCO, V. A., AND T. F. SAVOY. 1985. Effects of biotic and abiotic factors on growth and relative survival of young American shad, Alosa sapidissima, in the Connecticut River. Can. J. Fish. Aquat. Sci. 42: 1640-1648.

Crowder, L. B., J. A. Rice, T. J. Miller, and E. A. Marschall. 1992. Empirical and theoretical approaches to size-based interactions and recruitment variability in fishes. In D. DeAngelis and L. Gross [ed.] Individual-based approaches in ecology: concepts and individual models. Chapman and Hall, New York, NY.

Cushing, D. H. 1975. Climatic changes in life in the sea, p. 220-236. In D. H. Cushing [ed.] Marine ecology and fisheries. Cambridge University Press, Cambridge.

DEANGelis, D. L., AND C. C. CouTANT. 1979. Growth rates and size distributions of first-year smallmouth bass populations: some conclusions from experiments and a model. Trans. Am. Fish. Soc. 108: 137-141.

DEANGELIS, D. L., AND M. A. HUSTON. 1987. Effects of growth rates in models of size distribution formation in plants and animals. Ecol. Model. 36: 119137.

DeANGELIS, D. L., AND J. S. MATTICE. Implications of a partial-differentialequation cohort model. Math. Biosci. 47: 271-285.

DeAngelis, D. L., K. A. Rose, L. B. Crowder, and E. A. Marschall. 1993. Fish cohore dynamics: application of complementary modeling approaches. Am. Nat. (In press)

FOLKVORD, A., AND J. R. HUNTER, 1986. Size-specific vulnerability of northern anchovy, Engraulis mordax, larvae to predation by fishes. Fish. Bull. U.S. 84: 859-869.

FORNEY, J. L. 1976. Year-class formation in the walleye (Stizostedion vitreum vitreum) population in Oneida Lake, New York, 1966-1973. J. Fish. Res. Board Can. 33: 783-792.

GERRITSEN, J., AND J. R. STRICKLER. 1977. Encounter probabilities and community structure in zooplankton communities: a mathematical model. $J$. Fish. Res. Board. Can. 34: 73-82.

GREENE, C. H. 1986. Patterns of prey selection: implications of predator foraging tactics. Am. Nat. 128: 824-839.

GUTREUTER, S. J., AND R. O. ANDERSON. 1985. Importance of body size to the recruitment process in largemouth bass. Trans. Am. Fish. Soc. 114:317327

Henderson, M. A., AND A. J. CASs. 1991. Effect of smolt size on smolt-toadult survival for Chilco Lake sockeye salmon (Oncorhynchus nerka). Can. J. Fish. Aquat. Sci. 48: 988-994.

HoudE, E. D. 1987. Fish life dynamics and recruitment variability. Am. Fish. Soc. Symp. 2: 17-29.

1989. Comparative growth, mortality and energetics of marine fish larvae: temperature and implied latitudinal effect. Fish. Bull. U.S. 87: $471-496$.

Huston, M. A., D. L. DeAngelis, and W. M. Post. 1988. New computer models unify ecological theory. BioScience 38: 682-691.

Hutchinson, G. E. 1978. An introduction to population ecology. Yale University Press, New Haven, CT

LOMNICKI, A. 1988. Population ecology of individuals. Princeton University Press, Princeton, NJ. 223 p.

LotKA, A. J. 1925. Elements of physical biology. Williams and Williams Co., Baltimore, MD. 
Luecke, C., J. A. Rice, L. B. Crowder, S. F. Yeo, and F. P. Binkowski. 1990. Recruitment mechanisms of bloater in Lake Michigan: an analysis of the predatory gauntlet. Can. J. Fish. Aquat. Sci. 47: 524-532.

MCGURK, M. D. 1986 . Natural mortality of marine pelagic fish eggs and larvae: role of spatial patchiness. Mar. Ecol. Prog. Ser. 34: 227-242.

METHOT, R. D. 1983. Seasonal variation in survival of larval Engraulis mordax estimated from the age distribution of juveniles. Fish. Bull. U.S. 81: 741750 .

Miller, T. J., L. B. Crowder, J. A. Rice, and E. A. Marschall. 1988. Larval size and recruitment mechanisms in fishes: toward a conceptual framework. Can. J. Fish. Aquat. Sci. 45: 1657-1670.

PEPIN, P. 1990. Predation and starvation of larval fish: a numerical experiment of size- and growth-dependent survival. Biol. Oceanogr. 6:23-44.

Peterson, I., AND J. S. Wroblewski. 1984. Mortality rate of fishes in pelagic ecosystems. Can. J. Fish. Aquat. Sci. 41: 1117-1120.

POST, J. R., AND A. B. PRANKEVICIUS. 1987. Size-selective mortality in youngof-the-year yellow perch (Perca flavescens): evidence from otolith microstructure. Can. J. Fish. Aquat. Sci. 44: 1840-1847.

RICE, J. A., L. B. CROWDER, AND F. P. BINKOSWKI. 1987a. Evaluating potential sources of mortality for larval bloater (Coregonus hoyi): starvation and vulnerability to predation. Can. J. Fish. Aquat. Sci. 44: 467-472.

Rice, J. A., L. B. CROWDER, AND M. E. HolEY. 1987b. Exploration of mechanisms regulating larval survival in Lake Michigan bloater: a recruitment analysis based on characteristics of individual larvae. Trans. Am. Fish. Soc. 116: 703-718.

RiCKER, W. E. 1954. Stock and recruitment. J. Fish. Res. Board Can. 11:559 623.

Rosenberg, A. A., AND A. S. Haugen. 1982. Individual growth and sizeselective mortality of larval turbot reared in enclosures. Mar. Biol. 72: 73-77.

SALE, P. F. 1990. Recruitment of marine species: is the bandwagon rolling in the right direction? Trends Ecol. Evol. 5: 25-27.

SHARP, G. D. 1987. Averaging the way to inadequate information in a varying world. Am. Inst. Fish. Res. Biol. Briefs 16: 3-4.

Sinko, J. W., AND W. STREIFER. 1967. A new model for age-size structure for a population. Ecology 52: 331-335.

TAGGART, C. T., AND W. C. LeGGETT. 1987. Short term mortality in postemergent larval capelin Mallotus villosus. I. analysis of multiple in situ estimates. Mar. Ecol. Prog. Ser. 41: 205-217.

WARE, D. M., AND T. C. LAMBERT. 1985. Early life history of Atlantic mackerel (Scomber scombrus) in the southern Gulf of St. Lawrence. Can. J. Fish. Aquat. Sci. 42: 577--592.

WERNER, E. E., AND J. F. GLllam. 1984. The ontogenetic niche and species interactions in size-structured populations. Annu. Rev. Ecol. Syst. 15: $393-426$.

\section{Appendix}

The sytem under consideration is a fish cohort of individuals having different growth rates and suffering predation mortality with a probability that decreases with fish length. For cases in which the cohort can be described by a continuous distribution and in which the growth rates of individual fish do not vary randomly from day to day, it is possible to describe the changes in the size distribution of fish through time by means of a partial differential equation called the Sinko-Streifer model (Sinko and Streifer 1967). The model describes a system comparable with that described by the initial set of computer simulations in this paper. Whereas each simulation describes one specific possible outcome in this system, the Sinko-Streiffer model describes the long-term expectation. A second type of mortality, independent of size, can also be included or can be set to zero to correspond with simulations in the text.

Before formulating and solving this partial differential equation, let us define the relevant variables: $N_{0}=$ initial number of hatching fish, $s=$ fish length, $F(s, t)=$ fish length frequency distribution at time $t, s_{0}=$ initial length of fish (at hatching), $v=$ mean growth rate of fish (millimetres per day), $F_{v}(V)=$ distribution of growth rates, $v$, in the population

$$
=N_{0} \cdot \frac{1}{b \cdot \sqrt{2 \pi}} \cdot e^{-\frac{1\left(\frac{w-\widehat{v})^{2}}{2}\right.}{b^{2}}},
$$

$\Theta=$ individual probability of encounter and attack by a predator (per day), probability of capture given attack $=(13.5 / \mathrm{s}$ $-0.33)\left(s_{0}<s<s_{1}\right)$ or $=0\left(s_{1}<s\right)$ (based on the sizedependent capture success relationship from Luecke et al. 1990), $s_{1}=$ length above which size-dependent mortality (predation) does not occur, and $d_{n}=$ size-independent mortality rate coefficent (to correspond to simulations in text, $d_{n}=0$ ). Each fish in the population can be thought of as having a growth rate, $v$, chosen initially from the distribution $F_{v}(V)$. Each individual's growth rate remains constant over time.

The dynamics of the length frequency distribution of the cohort through time can be described by the partial differential equation

$$
\frac{\partial f}{\partial t}+v \frac{\partial f}{\partial s}=-\theta\left(\frac{13.5}{s}-0.33\right) \cdot f-d_{n} \cdot f .
$$

The solution of this equation for one single fish with growth rate $v$ is

$$
f(s, t ; v)=\delta\left(s-s_{0}-v \cdot t\right) \cdot \frac{e^{\left(0.33 \cdot \theta-d_{n}\right) \cdot \varepsilon}}{\left(1-\frac{v \cdot t}{s_{0}}\right)^{\frac{13.5 \cdot \theta}{v}}}
$$

where $\delta\left(s-s_{0}-v \cdot t\right)$ is the Dirac-delta function (see DeAngelis and Coutant 1979; DeAngelis and Mattice 1979; DeAngelis and Huston 1987).

To obtain $f(s, t)$, the size distribution for the whole population at time $t$, one must integrate $f(s, t ; v)$ multiplied by the growth rate distribution, $F_{v}(V)$, over all values of $v$. In the present model all growth rates are constrained to the range $(0,1)$ by setting $v=0$ for all values of $V<0$ in $F_{v}(v)$ and setting $v=1$ for all values of $v>1$ in $F_{v}(V)$. Then the integration yields

$$
f(s, t)=f_{1}(s, t)+f_{2}(s, t)+f_{3}(s, t)
$$

$$
f_{\mathrm{1}}(s, t)=F_{1} \cdot e^{-\left(\left(\frac{13.5}{s_{1}}-0.33\right) \cdot \theta+d_{n}\right) \cdot t} \quad\left(\text { for } s=s_{0} \text { only }\right)
$$

$$
f_{2}(s, t)=\frac{1}{b \cdot t \sqrt{2 \pi}} \cdot e^{-\frac{\left(s-s_{0}-\bar{v}\right)^{2}}{2 b^{2} t^{2}}} \cdot\left(\frac{s_{0}}{s_{1}}\right)^{\frac{13.5 \cdot \cdot \cdot \cdot t}{s-s_{n}}} \cdot e^{\left(0.33 \cdot \theta-d_{n}\right) t}
$$$$
\text { (for } \left.s<s_{1}, s<s_{0}+t\right)
$$

$$
\begin{array}{r}
f_{2}(s, t)=\frac{1}{b \cdot t \sqrt{2 \pi}} \cdot e^{-\frac{\left(s-s_{0}-\tilde{r}\right)^{2}}{2 b^{2} t^{2}}} \\
\cdot\left(\frac{s_{0}}{s_{1}}\right)^{\frac{13.5 \cdot \cdot \cdot t}{s-s_{0}}} \cdot e^{\left(\frac{0.33 \cdot \theta \cdot\left(s_{1}-s_{0}\right)}{s-s_{0}}-d_{n}\right) t}
\end{array}
$$

$$
\text { (for } \left.s>s_{1}, s<s_{0}+t\right)
$$

$$
f_{3}(s, t)=F_{3}\left(\frac{s_{0}}{s}\right)^{13.5 \cdot \theta} \cdot e^{\left(0.33 \cdot \theta-d_{n}\right) \cdot\left(s-s_{0}\right)}
$$

(where $s=s_{0}+t$ and for $s<s_{1}$ ) 


$$
f_{3}(s, t)=F_{3}\left(\frac{s_{0}}{s_{1}}\right)^{13.5 \cdot \theta} \cdot e^{\left(0.33 \cdot \theta-d_{n}\right) \cdot\left(s_{1}-s_{0}\right)}
$$

(where $s=s_{0}+t$ and for $s>s_{1}$ )

where

$$
F_{1}=\int_{-\infty}^{0} F_{v}(v) d v
$$

and

$$
F_{3}=\int_{1}^{\infty} F_{v}(v) d v .
$$

Because all fish are the same size at $t=0, f(s, t)$ can easily be converted to the distribution of growth rates in the cohort at time $t$. 